\title{
METAFÍSICA DE LA HUMILDAD EN LAS EMPRESAS MORALES DE JUAN DE BORJA
}

\author{
THE METAPHYSICS OF HUMILITY IN JUAN DE BORJA'S EMPRESAS \\ MORALES
}

\author{
David María González Cea \\ Universidad Nacional de Educación a Distancia \\ https://orcid.org/0000-0003-352I-6007
}

\begin{abstract}
The Hispanic emblematic tradition exhibits a profound preoccupation with moral and political doctrine. Its symbolic exposition of virtues rests on a metaphysical background. A metaphysical reading of Juan de Borja's Empresas Morales, and of other works of wisdom, is viable and advisable. These works portray an implied philosophy through images and Latin mottos. This idea is especially reinforced through the presentation of the virtue of humility.
\end{abstract}

KEYWORDS: Imprese; Empresas Morales; Juan de Borja; Doctrine; Metaphysical background; Humility.

RESUMEN • La tradición emblemática hispánica posee una profunda doctrina moral y política. Su exposición simbólica de las virtudes descansa sobre un trasfondo metafísico. Es posible y conveniente una lectura metafísica de las Empresas Morales de Juan de Borja, como de otras obras sapienciales. En ellas, a través de imágenes y lemas latinos, se representa una filosofía sobreentendida. Esto se confirma de manera especial en la exposición de la virtud de la humildad.

PALABRAS CLAVES: Empresa; Empresas Morales; Juan de Borja; Doctrina; Trasfondo metafísico; Humildad. 
La tradición sapiencial hispánica posee un rico trasfondo metafísico, a manera de nociones y principios sobreentendidos e incuestionados, propios del catolicismo cultural hispano. Es el fondo conceptual de una filosofía práctica aquilatada, expuesta en excelentes tratados de educación de príncipes, empresas, divisas, emblemas o aforismos. También la literatura participa de esta pedagogía del saber y del obrar juicioso y recto. Es un rasgo característico de nuestra traditio local, -desde la Edad Media hasta el fin del Barroco, y esencialmente en lo que se ha denominado Siglo de Oro- dotar a la reflexión ética de un empaque ontológico implícito.

Esta metafísica sobreentendida, en clave, casi siempre, aristotélico-tomista con tintes estoicos y senequistas, no exenta de tópicos neoplatónicos y humanistas, proporciona el supuesto teórico a la reflexión sobre las virtudes morales y políticas. Éstas, a la luz de un orden causal interno del que son "analogía escondida" y metadiscurso, adquieren su verdadera semántica iconográfica y completitud plástica. Conforman el numen subliminar de la pedagogía emblemática.

Este fondo filosófico constituye, por así decir, la entraña invisible, la estructura misma de la mentalidad sapiencial. Se despliega, como una imprimación ideológica previa, en la exposición de las virtudes, y sirve de andamiaje teórico a la reflexión sobre la humildad. En las Empresas Morales de Borja, incluso, adquiere una auténtica amplitud universal.

Juan de Borja, hijo de san Francisco de Borja, es educado en los principios de esta doctrina. La Compañía de Jesús sustenta en ella su labor pedagógica, anima con sus nociones y conceptos una obra apostólica e intelectual que no puede sino influir decisivamente en nuestro autor. $\mathrm{Y}$ «a pesar de que Juan de Borja no llegó nunca a formar parte de la Compañía de Jesús, las disposiciones e ideas que iban conformando la orden influirán con gran peso en el devenir de su vida» (Martínez y García, 2017: 74).

Nos encontramos, pues, ante una inteligencia de las cosas, y no sólo ante un conjunto de fórmulas doctrinales. Se trata, por así decir, de toda una sabiduría subintelecta. Es evidente «el gran peso que tienen los preceptos de la Compañía» (Martínez y García, 2017: 74) en la obra emblemática de este autor. Hasta tal punto, que la empresa se convierte en una composición de lugar ignaciana, en un cuerpo discursivo y plástico para las potencias del alma. La emblemática se transforma en "vehículo de transmisión de conceptos morales e ideológicos» (Martínez y García, 2017: 75), y por tanto en «lugar común transfigurado, desautomatizado" (Zafra, 2019: 88). Dando un paso en la hermenéutica jesuítica de la empresa de Borja, diremos que el emblema hispánico adquiere la potencia imaginativa de los Ejercicios Espirituales, y se instituye alegorización moral y política.

Sabido es el papel fundamental que la humildad, en todos sus grados, posee en la espiritualidad de san Francisco de Borja, como buen discípulo de san Ignacio de Loyola. No es de extrañar, por ello, la relevancia de esta virtud en la obra de su hijo, sobre todo a la hora de, como buen emblemista, desautomatizar las convicciones morales para convertirlas en virtud.

Porque es un hábito, el de la humildad, que, aunque radicado en la voluntad, es iluminado por el entendimiento: el autoconocimiento estoico, tan grato al pensamiento de nuestra época áurea, se funda en la conciencia clara, racional y exacta, del modesto papel que el hombre, causa segunda, tiene en el orden causal del universo.

El conocimiento de la acción subordinada de la causa segunda respecto de la Causa Primera, -que, según la doctrina tomista, no puede hacer nada por sí sola en el orden moral o político-, da apoyo a la conciencia humilde, pobre y abajada, autoconsciente de sus límites propios de agente creado. 


\section{NOCIÓN INTELECTUALISTA DE HUMILDAD}

Humildad, del latín hǔmǔlťtas, àtis, de humilis, "poca elevación, proximidad a la tierra», «condición humilde, pobre, baja, estado humilde», "pobreza de espíritu, apocamiento, debilidad de alma», «bajeza de origen» (Blánquez, 2012: 738), es definida por la RAE como "[v]irtud que consiste en el conocimiento de las propias limitaciones y debilidades y en obrar de acuerdo con este conocimiento» (<https://dle.rae.es> 15-08-2021).

La tradición sapiencial del Siglo de Oro insiste mucho en el carácter cognitivo de la humildad. Fray Luis de Granada, por ejemplo, en su Guía de pecadores, propone, como remedio contra la soberbia, mirarse "sin lisonja» a la luz de la verdad, porque "así como el principal fundamento de la humildad es el conocimiento de sí mismo, así el de la soberbia es la ignorancia de sí mismo» (LII, PI, Cap. IV, §I).

El tomista dominico Melchor Cano, en el cap. XV de su excelente Tratado de la victoria de sí mismo, con palabra vigorosa insiste, como medicina contra la soberbia, en considerar, frente a la grandeza de Dios, la propia nada, aportando un argumento metafísico y sobrenatural, extraído de la doctrina tomista de la premoción física. Insiste Cano en la necesidad de ver que todo el bien que tenemos procede de Dios, sin cuya gracia no se puede ni alcanzar ni conservar; y sintetiza la doctrina tomista al respecto, por la cual se exhorta al hombre a considerar que todos cuantos bienes en él hay, naturales como sobrenaturales, son prestados; para Cano, la conciencia de esta dependencia no sólo impide al hombre enaltecerse indebidamente, también lo obliga a tornarse más humilde.

El conocimiento de la condición humana, del estatus óntico que los seres humanos, causas segundas, tienen en común haciéndoles iguales en naturaleza, es su incapacidad para producir el bien por sí solos; la comprensión de esta insuficiencia es remedio contra la soberbia. La inteligencia de esta paridad entitativa previene contra el orgullo, es el fundamento por excelencia de la humildad. Esta visión senequista de la igualdad de condición de todos los seres humanos, tan cercana al cristianismo, integra el hábito virtuoso en una panorámica más vasta que la meramente moral o política.

Es por eso que, con gran perspicacia, Ramon Llull, en su Libro de la orden de caballería, entiende la soberbia como vicio de desigualdad. Humildad y fortaleza, en cambio, aman igualdad (PVI, §13), - esto es, el fundamento común, la indigencia ontológica que iguala a todas las criaturas racionales.

La humildad, en la tradición aristotélico-tomista, deriva de la templanza. La soberbia es intemperancia intelectual; pues, como dirá Alonso de Cartagena, «el escoger del destemplado no está regido por la razón» (Campos Souto, 2004: 293). Bajo esta luz, la soberbia es una opción del entendimiento no dirigida por el logos, sino por la concupiscencia.

Los autores de emblemas hispánicos coinciden, en general, con esta forma de fundamentar la humildad. Francisco Gómez de la Reguera, por ejemplo, comienza con una significativa cita de Séneca el comentario a su empresa de la pirámide (XII), para Enrique IV de Castilla: "Optimum es pati quod emendare non possis et Deum, quo auctore cuncta proveniunt, sine murmuratione comitari» (Epist. 108), "[l] o mejor es sufrir lo que no puedes enmendar, y seguir a Dios, de Quien proviene todo, por ser su autor».

Al principiar el cuerpo del comentario, Gómez de la Reguera va explicitando la metafísica sobreentendida, dando razones objetivas para sustentar la humilde confianza en Dios:

Si nada se hace sin causa, como dicen los filósofos, ¿cómo podrán obrar las segundas causas sin disposición de la primera, que es Dios? De cuya inmensa sabiduría dependen nuestras humanas 
acciones y sucesos, siendo árbitro y rector de todo lo criado, cuya divina providencia nos asiste, rige y defiende, y que quiere muchas veces fuera de nuestra opinión, aunque no de la razón, gobernarnos por accidentes y segundas causas, para mostrarnos así cómo su inmenso poder lo gobierna y dispone todo (Hernández, 1991: 124).

En esta línea, que es común a obras y autores de nuestros siglos áureos, afirma Juan de Borja en la empresa 60 "[d] e cuanta importancia sea al hombre su propio conocimiento". Este autoconocimiento remite siempre a la Causa de las causas, por lo cual es de lógica aplastante que cuanto más conozca el hombre su propia condición, «cuanto cada uno aprovechare en su propio conocimiento, tanto medrará en el de Dios». No conviene, por tanto, «ser perezosos, en tratar de conocernos» (Borja, 1981: 120). ${ }^{1}$

\section{LA ESPIRAL DEL AUTOCONOCIMIENTO}

El repliegue cognoscitivo del sujeto sobre su propia condición en el orden creado es figurado mediante el zoomorfismo del caracol. La espiral logarítmica, en la figura del molusco, en esta empresa 60, refleja bien esta dinámica del autoconocimiento, pues el incremento en la distancia de sus brazos, como discretamente muestra la concha del caracol representado, es alegoría de la progresión geométrica: el aumento de conocimiento, en función de un logos de crecimiento perfectivo, multiplica la virtud. Y así, cuanto más se pliega ad intra el yo sobre su propia condición, en un movimiento de interiorización intelectual, más se despliegan sus potencialidades ad extra.

Es significativo, en la empresa del caracol, reconocer a Persio detrás, por la filiación estoica de su lema "Ne te quaesieris extra» (Martínez Sobrino, 2013a: 92). El mote nos expresa lo que muestra la imagen. Y aquí conviene explicar cómo funciona la referencia simbólica, en cuanto que alegórica.

Por una parte, existe un vínculo que, en cierto sentido, es convencional, porque "puesto que el símbolo es un signo arbitrario cuya relación con el objeto se determina arbitrariamente», permite, por variación simbólica, "otorgar una nueva dimensión a la imagen», para hacer de ella "símbolo de humildad y de autosuficiencia» (Martínez Sobrino, 2013a: 96).

Pero en cuanto que al mismo tiempo que convencional es sígnica, la referencia alegórica no es sólo arbitraria. La forma de la figura muestra, aunque no lo diga, ${ }^{2}$ algo existente, un indicio de un concepto o un principio del conocimiento, con el que guarda una relación formal. Y así, una línea curva que discurre hacia un centro es figura natural de la introspección, y en sentido amplio, puede decirse que muestra un movimiento de interiorización

1. Cito los pasajes de Borja actualizando un tanto la ortografía, la grafía y la puntuación. Asimismo, modifico en ocasiones la traducción de los lemas de Borja y otros autores mencionados, cambiándola un poco para ajustar su sentido.

2. Utilizamos aquí la distinción wittgensteiniana entre «decir» y «mostrar», importante, a nuestro juicio, para el análisis de la iconografía emblemática. Y, ante todo, para comprender cómo funciona psicológica e intelectualmente el símbolo: por un lado, sirve para representar algo invisible, arbitraria o convencionalmente; por otro lado, muestra, como indicio estético, un patrón cognitivo o mental. Coherentemente con la doctrina tomista sobre el signo, que, como explica Juan de santo Tomás (Cf. Summularium, I, 2; II, q. 21) entiende como aquello que presenta al entendimiento una cosa diferente de sí, pero como haciendo de vicario o representante suyo, llevando la inteligencia a la cosa por un camino de conocimiento a priori, o, indudablemente, por cierta relación analógica o de procedencia. 
autocognitiva. Una traza curva centrífuga, por el contrario, manifiesta un sentido expansivo que refleja, por sí misma, un fluir hacia el exterior [fig. 1].

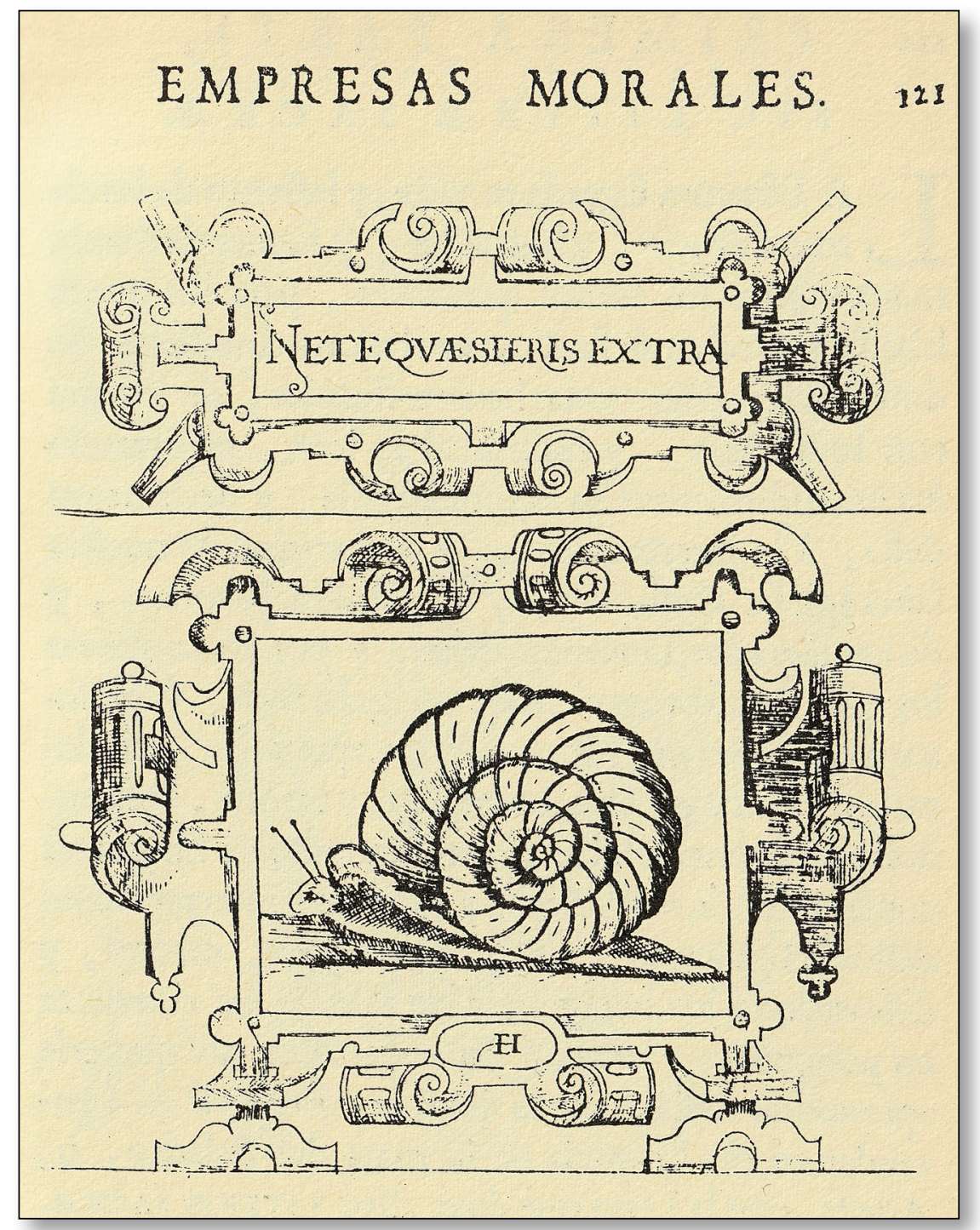

Fig. 1. Juan de Borja, Empresas Morales, 1981. Empresa 60.

De esta forma, la estética se convierte en inteligencia natural, no por dicción intelectiva, sino por referencia sígnica. Con esto, las resonancias internas de las figuras, en clave también neoplatónica y humanista, remiten a conceptos interiores, al pensamiento sobreentendido. ${ }^{3}$

3. La filiación neoplatónica y humanista de la emblemática de Borja, apelando al "significado de la imagen» (Martínez Sobrino, 2013a: 97) además de al significado de la palabra, es perfectamente coherente con el aristotelismo tomista. Pues, recordemos, el tomismo contiene todo lo mejor de Platón y san Agustín.

IMAGO, NÚM. 13, 2021, 53-66 
El autoconocimiento del humilde redunda en una acción más eficaz en su entorno; tras admitir la necesidad de la moción divina, ${ }^{4}$ necesaria por la propia incapacidad, admite un factor progresivo de autoexpansión creciente. De esta forma, es tópico en la tradición sapiencial hispánica el éxito transcendental que espera al humilde, frente al fracaso final que aguarda al soberbio.

El autoconocimiento en el que tanto inciden los autores de emblemas y aforismos, y Borja en concreto, tiene por tanto, primero, un sabor senequista, y segundo un sustrato aristotélico-tomista muy claros: es la consideración reflexiva del orden causal, en que se inserta la causa segunda, el argumento más sólido para crecer en humildad.

\section{UN ORDEN CAUSAL BIEN CONCERTADO}

El orden causal bien concertado se representa con la imagen del reloj, tan querida por la tradición hispánica; además de ser figura de una buena disposición de la vida institucional y social, es analogía de lo que Francisco de Quevedo denominará Política de Dios. En un plano metafísico, el reloj concierta con las piezas, que son las causas segundas. «El Reloj, -dice Borja en la empresa 196- aunque de todo ande bien concertado, si no estuviese puesto con el Sol, no será de provecho» (Borja, 1981: 398).

Se asigna entonces al astro rey el papel de Primer Motor transcendente al orden mismo. Seguir al Primer Motor nos habilita "para gobernar por él nuestras acciones», de manera que, sigue diciendo en el mismo sitio, "cada uno se acierte, a gobernar a sí mismo".

El lema de esta empresa sintetiza la perspectiva central del asunto: "A supremo dirigatur", que en la tabla de empresas del final traduce en clave tomista: "andará bien, si se rige por Dios». Es el principio básico de esta doctrina de las causas segundas, y más aún, de la premoción física sobrenatural, que papel tan relevante tendrá en la disputa contra los protestantes y contra el semipelagianismo renacentista. Rastreamos aquí, incluso, la predeterminación física, según la cual el Primer Motor, rigiendo en los motores segundos, produce sus actos más genuinos. ${ }^{5}$ La moción divina, según el Aquinate, mueve la voluntad de la causa segunda a moverse por sí misma, por lo que ésta andará bien si es regida por la Causa Primera. Los agentes creados adquieren su autenticidad como efecto de la moción divina.

La causa segunda, en la doctrina aristotélico-tomista, no ha de pretender moverse por sí sola. Porque, expone la empresa 195, "en conseguir, lo que pretende, consiste todo su daño"; y es que la causa segunda, sin el impulso de la Causa Primera, "se desvanece, como el humo" (Borja, 1981: 396). Borja lo muestra de nuevo, en la empresa 186, con la imagen del Sol, Primer Motor, hablando bellamente del amor divino: «El amar a Dios sobre todas las cosas, es el primero mandamiento, y el que más nos importa, pues nadie lo puede amar, sino siendo amado primero por Él» (Borja, 1981: 378). ${ }^{6}$

4. Incluso para los actos libres, como enseña el tomismo. Véase Apología bañeciana contra molinistas.

5. Doctrina fundamental del tomismo hispánico, sobre todo de Báñez.

6. Nótese el matiz tomista, con sabor claro a premoción: «siendo amado primero por Él». Quién podría no contemplar aquí la doctrina clásica de la premoción divina, que siempre precede al movimiento de la causa segunda, tanto en un plano natural como sobrenatural. Premoción que Domingo Báñez entiende como predeterminación, y que es, realmente, una causación previa al movimiento libre de la criatura racional. Es la enseñanza católica de Trento y Orange II sobre la prioridad de la moción divina, natural o sobrenatural, aquí dada por supuesta como trasfondo doctrinal. 
El reloj bien concertado, en la tradición emblemática, simboliza la eficacia causal. Nos hace pensar en la procesión de la moción divina, que mueve concertadamente la voluntad, para que actúe con diligencia en bien del conjunto. Sebastián de Covarrubias, en sus Emblemas Morales, 1610, en "Pondere levior», «más leve por el peso», (Cent. 2, Emb, 42, fig. 142), representa la facilidad con que actúa la causa segunda integrada en el plan de causaciones libres diseñado por Dios; transmitiendo que el hombre, cuanto más de peso es su virtud, «nunca está desconcertado», como el reloj (Bernat y Cull, 199: 683).

El reloj de ruedas, en la Emblemática, depende del Reloj de Sol, como vemos también en Núñez de Cepeda, en su emblema "Regit et corrigit», "rige y corrige», -lema que repite Saavedra-Fajardo en sus Empresas- : el reloj de ruedas, diríamos el organismo causal, "[n]ecesita de tener a la vista el reloj de Sol, que le [...] ayude» con sus mociones, como si dijéramos, pues, de Primer Motor. A estas mociones del sol sobre el reloj denominaba Covarrubias «buenas inspiraciones» (Bernat y Cull, 1999: 683-684). La semejanza con la doctrina de la gracia es patente, puesto que las gracias actuales son, precisamente, inspiraciones [fig. 2].

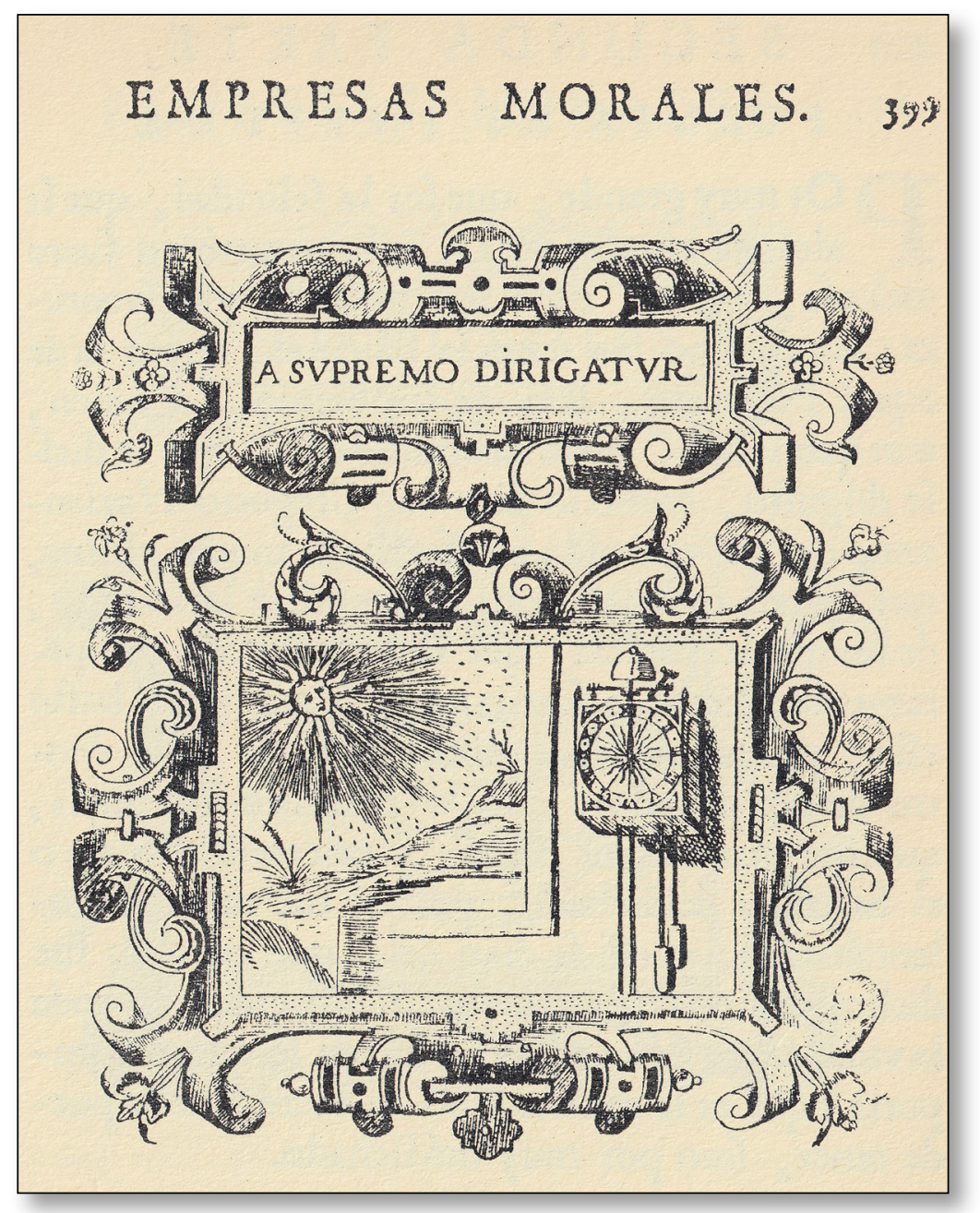

Fig. 2. Juan de Borja, Empresas Morales, 1981. Empresa 196.

IMAGO, NÚM. 13, 202I, 53-66 


\section{LA FATAL PRETENSIÓN DE LA CAUSA SEGUNDA. LA HORMIGA}

En la empresa 216 se proponen a imitación las acciones de las hormigas, que ejercen su providencia particular o buen gobierno de la res publica, "con razón, memoria, ingenio y cuidado» (Borja, 1981: 438). El problema surge «cuando les nacen las alas», y "quieren volar más de lo que les conviene». Es por su mal, como reza el lema, que quieren actuar por sí solas.

Así, el mensaje glosado tiene, primero, una lectura política. La hormiga sin alas, siendo parte eficaz del todo, no debe pretender tener una capacidad más allá de su naturaleza o estado. Borja insiste, en el mismo lugar, en que «[e]l camino más cierto, para perderse, es, querer subir más, de lo que cada uno debe en su estado».

La causa segunda, en este caso figurada por la hormiga, -no por la hormiga voladora, sino por la que carece de alas, y está abajo, en la tierra, integrada en la maquinaria del hormiguero, como una parte del todo-cuando pretende actuar por sí sola, como causa eficiente que no es, lo hace "in suum dispendium», es decir, "para su propio daño». Puede interpretarse en clave tomista: sólo cuando es movida por el Primer Motor es un agente benéfico del conjunto. Cuando pretende tener alas para hacerse causa eficiente de sí misma, es en perjuicio propio, pues por sí sola, sólo para el mal. ${ }^{7}$

En la tradición emblemática, la hormiga es figura del conocimiento de los propios límites. Así, en el emblema de Núñez de Cepeda que tiene por lema «pro munere tanto exiguae vires", "con tan fuerzas exiguas para el deber", se representa como temeridad la pretensión de la hormiga de cargar el orbe sobre sí sola, y apela en clave estoica al autoconocimiento y a la prudencia. En la subscriptio, se dice «[p]rudencia será reconocer primero las fuerzas, que cargar sobre ellas tan grave peso que las oprima» (Bernat y Cull, 1999: 427).

La causa segunda, sabiendo con cuán exiguas fuerzas cuenta para la acción moral, ejercita la prudencia apelando a un principio superior que la auxilie: estar inserta en un orden causal dado, como la hormiga en su hormiguero [fig. 3].

\section{CON LUZ NATURAL. LA LUMBRE Y EL CÍRCULO}

El ser causa segunda es por participación del ser divino, pues esto es lo propio de los seres creados. En recibir el ser reside su dignidad. En la empresa 190 Borja lo da a entender de esta forma: "Gran dignidad es la del Hombre, pues demás, y de tantas, y tan grandes mercedes, como Dios Nuestro Señor usó con él, criándole, y redimiéndole, y dándole el ser, y sustentándole, y dándole todo lo criado en la tierra» (Borja, 1981: 386).

Se expresa con cierto regusto molinista, propio de la escolástica jesuítica, al matizar que «no dejará Nuestro Señor de concurrir con él, para que sus obras sean hechas en su gracia».

«La inmensa bondad de Dios en ningún tiempo desamparó a los hombres», afirma el autor en la empresa del círculo (Borja, 1981: 382-383). Dios dio a los seres humanos «lumbre natural, para que por ella pudiesen alcanzar, que había Dios, y además de este conocimiento les dio un Libro, que es el de las criaturas, para que por el rastro de ellas, hallasen a su Criador, y por las perfecciones de ellas viniesen en conocimiento de las perfecciones de Dios» (Borja, 1981: 382).

7. Recordemos a este propósito el canon 22 del Concilio de Orange, tan importante en la doctrina tomista: «De lo propio de los hombres. Nadie tiene de suyo propio, sino falsedad y pecado». 


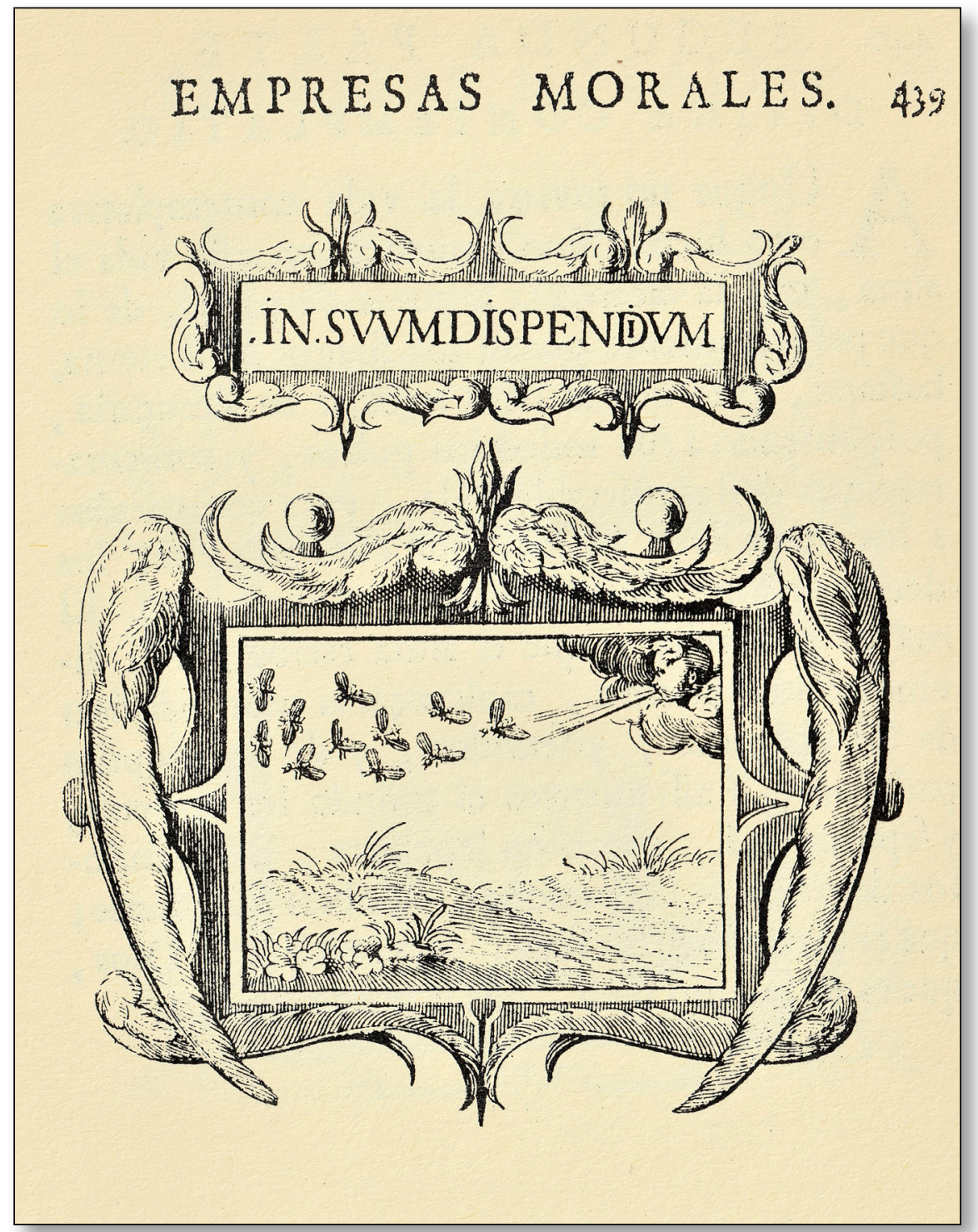

Fig. 3. Juan de Borja, Empresas Morales, 1981. Empresa 216.

Este orden causal es representado por el círculo en esta empresa 188. Dios, Primer Motor, es «como el punto indivisible del centro del círculo, y todas las criaturas, como líneas que proceden del centro a la circunferencia: y así toda la hermosura, y perfección de las criaturas, son rayos, que nos alumbran, y enseñan la suma bondad y hermosura que en Dios hay". 


\section{VALIENTE INDIGENCIA DE LA CAUSA SEGUNDA. EL ESCARABAJO}

El ser humano, causa segunda, depende absolutamente de la Causa Primera. Esta dependencia tiene dimensiones morales, políticas y sociales. Las Empresas Morales la dan por supuesta de muy diversas formas.

En la Empresa del escarabajo insiste don Juan de Borja en que es grande la miseria del hombre "sólo de por sí», y da por sentada la necesidad de la moción divina para una acción verdaderamente libre; es grande la indigencia de la criatura racional por sí sola, «si no se le ajunta -dice- la gracia sobrenatural, que es la que le da la verdadera forma, y ser" (Borja, 1981: 340) [fig. 4].

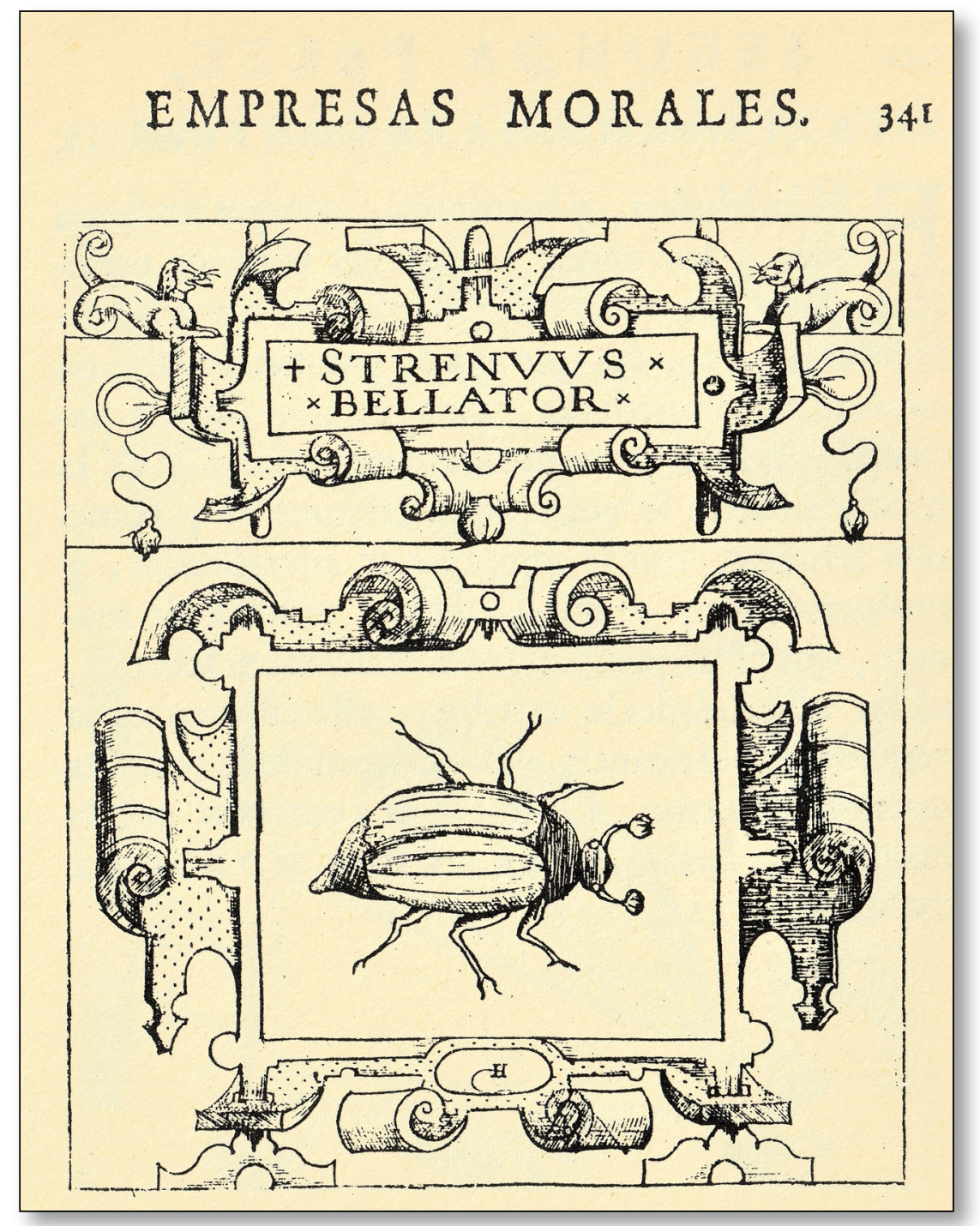

Fig. 4. Juan de Borja, Empresas Morales, 1981. Empresa 167. 
En esta ocasión lo expresa menos conforme con la doctrina tomista de la moción sobrenatural, pues el verbo ajuntar tiene el sentido voluntarista de socorrer concurriendo, acudir en ayuda codo con codo, añadirse cualitativamente. Pero la idea principal permanece: es gracias al socorro del Primer Motor que el hombre puede actuar esforzadamente, a imagen del valeroso escarabajo, figura de la fortaleza, como apunta el lema que ilustra la pictura: «Strenuus bellator», que en la tabla de empresas se traduce como "guerreador valiente». Por tanto, la causa segunda por sí sola no es nada, pero movida por la Causa Primera es potente.

Por el pecado original, el hombre ambiciona ocupar el lugar de la Causa Primera. Pero, como advierte Borja en la empresa 169, "[por muy dificultosa cosa se tiene, el renunciar uno [...] su pretensión» (Borja, 1981: 344). El falso «derecho» que cree tener la causa segunda de ser causa primera es su tentación, su seréis como dioses.

Esta tentación adámica procede de un exceso de confianza en las solas fuerzas, por las que la criatura racional cree poder ser causa eficiente de su perfección. Borja expone con claridad la dependencia de la causa creada, el hombre, respecto de la primera, su Creador, tanto en un plano natural como sobrenatural, en la empresa 161:

Grandísimos han sido los daños, que han sucedido a los hombres, que han querido poner su confianza en sus fuerzas, y en su poder, por ser tan corto, y tan limitado todo el poder humano, cuando no se juntare con el ayuda, y favor divino; del cual sólo debe esperar el favor, y remedio en los trabajos grandes, y pequeños (Borja, 1981: 328).

Hay que precisar que, por un momento, la expresión «se juntare» parece tener, de nuevo, un sabor molinista. Sin embargo, la expresión "del cual solo debe esperar el favor", devuelve el pasaje a sede tomista, porque remite todo el bien causado a la moción divina.

\section{TELEOLOGÍA DE LOS SERES CREADOS. EL PERRO Y LA PIEDRA}

Los seres creados, en la doctrina clásica, tienden al fin último para el que han sido creados. Esta teleología está presente, como un trasfondo conceptual asumido, en las obras sapiencias de la tradición hispánica.

Es elocuente, al respecto, la empresa 156 (Borja, 1981: 318-319), que es, significativamente, la empresa de la meta o término: «Respice», «mira al fin». En ella habla Borja de «los que viven sin acordarse del fin, para el que fueron criados»; del peligro de perderse "por no ver el fin», "que es adonde hay de ir a parar». Perderse, pues, es no alcanzar el fin último, de ahí la necesidad de "que miremos al fin, y al paradero, que todo ha de tener». Es significativa la imagen de la meta romana para representarlo: el "que allí llegase primero" ganaba el precio del "camino derecho de la virtud".

La empresa 137, del perro que muerde la piedra, manifiesta la convicción de que «todo nos viene de la mano de Dios» (Borja, 1981: 280), o lo que es lo mismo, todo lo bueno procede del Primer Motor, como de su fuente causal. Tanto el bien, efecto bueno movido, como el mal, efecto malo permitido, vienen «de su mano" y "para nuestro provecho». De aquí la importancia de agradecer tan grande necesidad de Dios, cuya base no es más que la absoluta dependencia de los agentes creados respecto de la Causa Primera.

Pero, como el perro al que lanzan un pedrusco, «que cuando le tiran la piedra, va primero a morderla, que a quien se la tiró", el ser humano no se remonta al autor, por moción, o al permitidor, por permisión, de los efectos, sino a los efectos mismos.

IMAGO, NÚM. 13, 2021, 53-66 
El lema de esta empresa, "Non in lapidem», "no contra la piedra», insta a remontarse al Autor, por cuya autoridad se sabe la bondad del suceso, sea merced, sea castigo [fig. 5].

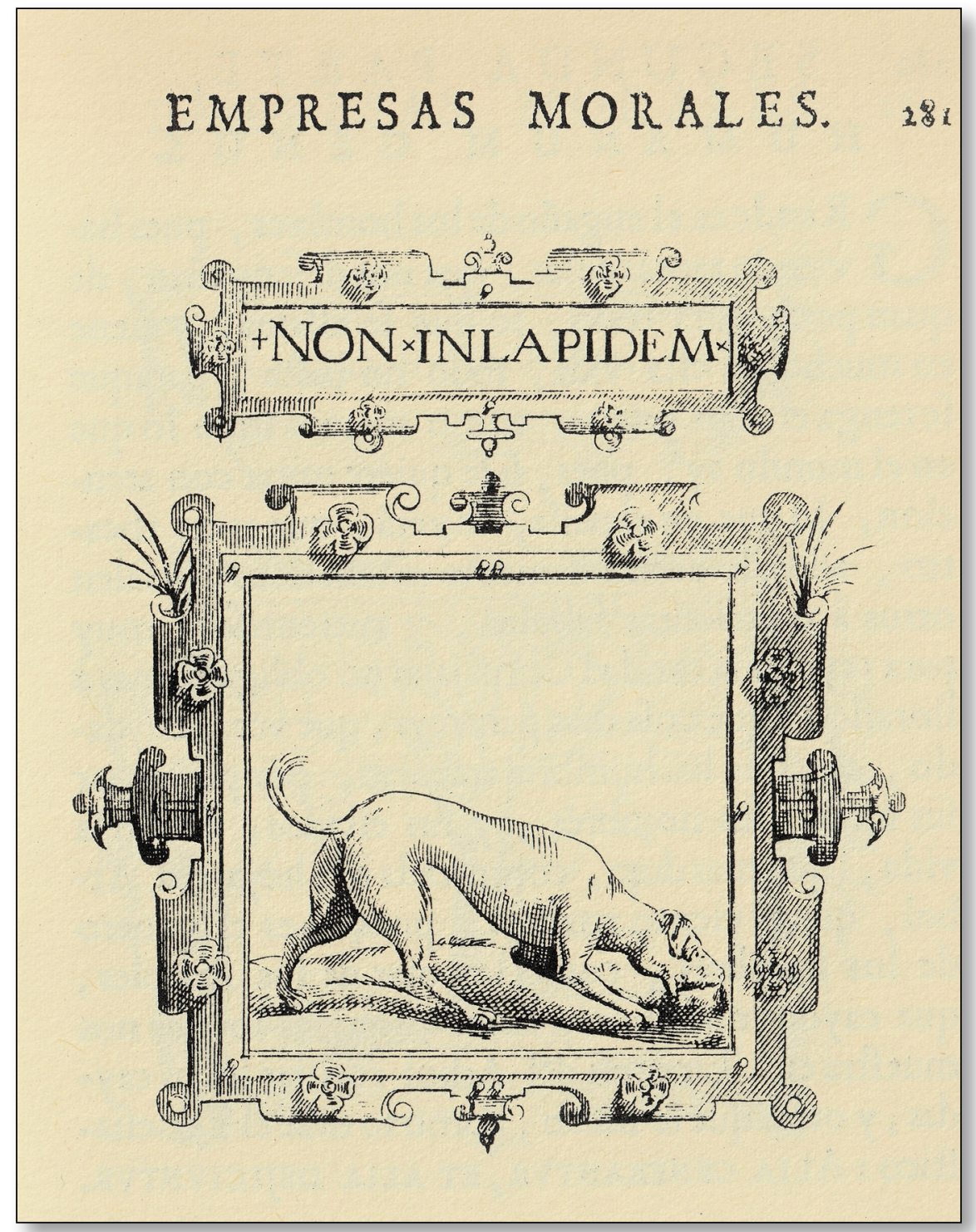

Fig. 5. Juan de Borja, Empresas Morales, 1981. Empresa 137.

Recordemos que en Alciato se repite el motivo. En el emblema cuyo lema en latín es "Alius peccat, alius plectitur», "pagan justos por pecadores», bajo la imagen de un hombre que va a volver a lanzar una piedra, un perro muerde la primera, enunciando la subscriptio: «Muerde la piedra el perro, mas no sigue al que se la tiró» (Bernat y Cull 1999: 641). 


\section{UN ORDEN CAUSAL CONSONANTE. LA MÚSICA}

Los símbolos musicales son también de suyo aptos para la suposición de contenidos metafísicos. En la empresa del órgano (Borja, 1981: 252-253), bajo el lema «Non impedire», se puede sobreentender la necesidad de no resistir la moción del Primer Motor. No se debe impedir la gracia para favorecer la "consonancia interior». Ésta consiste en que las obras, armonizadas con las palabras, «sean buenas».

La voluntad ha de consentir el auxilio divino y no impedirlo, de manera que la criatura racional, y la moción con que la Primera Causa quiere moverla a consonancia moral, anden bien concertadas.

La armonía musical es imagen, en la tradición sapiencial, del orden causal social bien temperado. En su empresa 61, Saavedra Fajardo elogia la armonía de este ordenamiento público de los vasallos, causas segundas del entramado socio-político, en orden al bien común, en que "obedece un pueblo de cuerdas, todas templadas y todas conformes en la consonancia» (Saavedra Fajardo, 1988: 430).

\section{ACUÉRDATE QUE ERES HOMBRE}

Recuerda que eres sólo una causa segunda, acuérdate que eres solamente un ser humano, «Hominem te esse cogita» (Borja, 1981: 198-199). Tal parece ser la exhortación imperiosa que domina las Empresas Morales. Este principio metafísico, que deviene antropología de la humildad, fundamenta la moral del autoconocimiento, en clave indudablemente estoica, que domina ambas partes de la obra.

De saber que sólo se es una causa segunda, incapaz de obrar por sí sola con las solas fuerzas, salvo para el propio daño, procede la primera convicción que transmiten las empresas: las obras, por sí solas, no son meritorias; lo obligado, por convicción, es el reconocimiento humilde "[d] c cuán poco valor sean nuestras obras solas ellas, y de por sí» (Borja, 1981: 244).

Porque, en definitiva, como enseña el autor en su empresa 117, (Borja, 1981: 240-241) "[g]randes son los castigos, y los daños, que ha sucedido a los hombres, que confiando en sus propias fuerzas y poder, han querido emprender cosas grandes».

Dios, Primer Motor y Causa Primera de todo bien, da «grandes victorias a los humildes».

\section{CONCLUSIÓN}

Las Empresas Morales contienen una riquísima doctrina metafísica, en la cual fue educado Juan de Borja, y por la cual su discurso emblemático es fecundo en resonancias ontológicas. Es un trasfondo intelectual sobreentendido que aflora, como sustancia nutricia, en la composición de los motivos de la empresa.

La hormiga, que inserta en el orden causal de su hormiguero contribuye al bien común; el reloj, cuya eficacia es referida a un Primer Motor; la completitud del círculo, perfecta imagen de la estructura teleológica del mundo creado; la autenticidad del escarabajo, verdadera causa segunda de su obrar; o la armonía musical del órgano, de cuya consonancia abstraer

IMAGO, NÚM. 13, 2021, 53-66 
analogías para la paz social; son ejemplos, entre otros, de una cierta figuración simbólica de la virtud de la humildad radicada en la naturaleza de las cosas. Consiste esencialmente en reconocerse parte de un sistema de causalidades bien concertado, en que no caben pretensiones egoístas. Pues no hay razón más ajustada para ser humilde que saberse causa segunda, y no primera. Y no hay fundamento más recio que la propia condición humana.

\section{BIBLIOGRAFÍA}

Bernat Vistarini A., y Cull, J. T. [1999]. Enciclopedia de Emblemas Españoles Ilustrados, Madrid, Akal.

Blánquez, A. [2012]. Diccionario latino-español, Barcelona, Editorial Gredos.

Borja, J. [1981]. Empresas Morales, ed. facsímil e introducción de Carmen Bravo-Villasante, Madrid, Fundación Universitaria Española.

Campos Souto, Mar. [2004]. El «Memorial de virtudes»: la traducción castellana del «Memoriale virtutum» de Alfonso de Cartagena, Burgos, Instituto Municipal de Cultura.

Cano, M. [1860]. Tratado de la victoria de sí mismo, Barcelona, Librería Religiosa.

García Mahíques, R. [1998]. Empresas Morales de Juan de Borja, Imagen y palabra para una iconología, Ajuntament de València.

García Román, C., y Martínez Sobrino, A. [2017]. "Las Empresas morales de Juan de Borja instrumento de pedagogía jesuítica», Imago, 9, 73-86. <http://dx.doi.org/10.7203/ imago.9.10831>.

Gómez de la Reguera, F. [1991]. Empresas de los Reyes de Castilla y de León, Edición crítica de César Hernández Alonso, Valladolid, Secretariado de Publicaciones de la Universidad de Valladolid.

Granada, Fr. L. de. [1986]. Guía de Pecadores, Ed. de José María Balcells. Barcelona, Editorial Planeta.

Hernández Alonso, C. [1991]. Edición y estudio crítico de las Empresas de los reyes de Castilla y León de Francisco de la Reguera, Valladolid, Secretariado de Publicaciones de la Universidad de Valladolid.

Lull, R. [1992]. Libro de la orden de caballería, L. A. de Cuenca (trad.), Madrid, Alianza Editorial.

Martínez Sobrino, A. [2013a]. "La empresa 60 de las Empresas Morales de Juan de Borja. Posible origen textual de la imagen del caracol», Imago, 5, 91-99. <doi: 10.7203/ imago.52607>.

Real Academia Española: Diccionario de la lengua española, 23. a ed., [versión 23.4 en línea]. <https://dle.rae.es> [15/08/2021]

Saavedra Fajardo, Diego de. [1988]. Empresas políticas, Ed., introducción y notas de Franco Javier Díez de Revenga, Barcelona, Planeta.

Zafra, R. [2019]. «Emblemas doctrinales», Imago, 11, 85-95. <http://dx.doi.org/10.7203/ imago.11.16017>. 